\title{
Polypropylene/calcium carbonate nanocomposites - effects of processing techniques and maleated polypropylene compatibiliser
}

\author{
M. Y. A. Fuad ${ }^{1}$, H. Hanim 1 , R. Zarina1, Z. A. Mohd. Ishak², Azman Hassan ${ }^{3}$ \\ 1Plastics Technology Group, Advanced Materials Research Centre, SIRIM Berhad, P.O. Box 7035, 40911 Shah Alam, \\ Malaysia \\ ${ }^{2}$ School of Materials and Mineral Resources Engineering, Engineering Campus, Universiti Sains Malaysia, \\ Seri Ampangan, 14300 Nibong Tebal, Penang, Malaysia \\ ${ }^{3}$ Faculty of Chemical and Natural Resources Engineering, Universiti Teknologi Malaysia, Skudai, Johor, Malaysia
}

Received 8 April 2010; accepted in revised form 17 June 2010

\begin{abstract}
The mechanical properties and crystalline characteristics of polypropylene (PP) and nano precipitated calcium carbonate (NPCC) nanocomposites prepared via melt mixing in an internal mixer and melt extrusion in a twin screw extruder, were compared. The effect of maleic anhydride grafted PP (PP-g-MAH) as a compatibiliser was also studied using the internal mixer. At low filler concentration of $5 \mathrm{wt} \%$, impact strength was better for the nanocomposites produced using the internal mixer. At higher filler loading of more than $10 \mathrm{wt} \%$, the extrusion technique was more effective to disperse the nanofillers resulting in better impact properties. The impact results are consistent with the observations made from Scanning Electron Microscope (SEM) morphology study. As expected, the flexural modulus of the nanocomposites increased with filler concentration regardless of the techniques utilised. At a same filler loading, there was also no significant difference in the moduli for the two techniques. The tensile strength of the mixed nanocomposites were found to be inferior to the extruded nanocomposites. Introduction of PP-g-MAH improved the impact strength, tensile strength and modulus of the mixed nanocomposites. The improvements may be attributed to better interfacial adhesion, as evident from the SEM micrographs which displayed better dispersion of the NPCC in the presence of the compatibiliser. Though NPCC particles have weak nucleating effect on the crystallization of the PP, addition of PP-g-MAH into the mixed nanocomposites has induced significant crystallization of the PP.
\end{abstract}

Keywords: nanocomposites, polypropylene, mechanical properties, nano-sized calcium carbonate, melt compounding

\section{Introduction}

The development of polymer nanocomposites (PNCs) can be regarded as a significant technological advancement in the plastics industry over the past few years. PNCs are formed from blends of nanometer sized fillers with either thermoplastics or thermosetting polymers. Numerous benefits of PNCs have been described which include improvements in mechanical properties, barrier properties, heat resistance, dimensional stability and flame retardancy [1-4]. There are many types of nanosized fillers being used among which include nanofibres such as carbon nanotubes or cellulose whiskers, nanoplatelets such as layered silicate and nano-sized isotropic particles such as silica or calcium carbonate $\left(\mathrm{CaCO}_{3}\right)$ [5-8].

$\mathrm{CaCO}_{3}$ is one of the most commonly used fillers in thermoplastics, especially polyolefins. It is inexpensive and can be used at high loadings. Originally used as a cheap extender, fine grades of 
precipitated $\mathrm{CaCO}_{3}$ is now being produced in nanometer size and this nano precipitated $\mathrm{CaCO}_{3}$ (NPCC) has the potential to be an important functional filler in polypropylene composites [9-12]. The surface of the NPCC filler is usually treated with fatty acids such as stearic acid, to modify the filler surface to become hydrophobic. The main purpose for this surface coating is to reduce moisture absorption and hence particle agglomeration during storage, as well as to improve dispersibility of the polar filler when incorporated into non-polar polymer melts [13]. Improved dispersion of the nanofillers within the polymer matrix is a prerequisite for any improvement in mechanical properties, particularly impact strength.

Polypropylene (PP) is a very versatile and adaptable polymer whereby its properties can readily be enhanced with the inclusion of various types of fillers. The advantages gained in price/volume/performance relations have resulted in PP composites successfully penetrating fields traditionally occupied by other engineering materials [14]. Generally, the properties of particle-filled PP are strongly dependent on the characteristics of the filler particles. Due to its non-polar chemical structure, PP interacts poorly with the typically polar fillers such as $\mathrm{CaCO}_{3}$, and optimum dispersion is normally difficult to achieve. Compatibilisers are frequently used to improve the interfacial adhesion between $\mathrm{CaCO}_{3}$ and PP, in order to gain the envisaged enhancement in mechanical properties. Bi-functional molecules such as maleic-anhydride grafted PP (PP-g-MAH) are commonly used as a compatibilisers for $\mathrm{PP}$ and $\mathrm{CaCO}_{3}[15,16]$.

Besides filler surface modification and addition of suitable compatibilisers, the choice of processing techniques also plays an important role to achieve the desired improvement in the properties of interest. The efficiency of the processing techniques to disperse the fillers becomes critical, especially with nanofillers which have very strong tendency to agglomerate due to their high surface energies. The two common melt-processing techniques employed to produce nanocomposites are melt mixing using an internal mixer and melt extrusion using a twin screw extruder. Compared to an internal mixer, a twin screw extruder is more convenient to compound nanocomposites in larger quantity and continuous process. It has been reported nanocompos- ites of PP with nano-sized $\mathrm{CaCO}_{3}$ have been successfully prepared via melt mixing by Chan $e t$ al. [17]. The good filler dispersion obtained using the internal mixer has resulted in significant improvements in modulus and impact strength with only a slight lowering of the tensile strength.

Wang et al. [18] used three kinds of compatibilizers to study the effect of interfacial interaction on the crystallization and mechanical properties of polypropylene (PP)/nano- $\mathrm{CaCO}_{3}$ composites. The compatibilizers were PP grafted with maleic anhydride (PP-g-MA), ethylene-octene copolymer grafted with MA (POE-g-MA), and ethylene-vinyl acetate copolymer grafted with MA (EVA-g-MA). They noted that only the former compatibilizer resulted in significant improvement the dispersion of nano- $\mathrm{CaCO}_{3}$ particles, favoured the nucleation effect of nano- $\mathrm{CaCO}_{3}$, increased the tensile strength and modulus. The ductility and impact strength of composites were however compromised as tradeoff to the improvement of the other mechanical properties.

The objective of this study is to compare the properties of PP filled with NPCC prepared via two different routes viz. melt mixing in an internal mixer and melt extrusion in a twin screw extruder. The mechanical properties of the nanocomposites are evaluated using impact, flexural and tensile tests. Thermal and crystallisation characteristics are analysed using a Differential Scanning Calorimeter (DSC) while filler dispersion is observed using a Scanning Electron Microscope (SEM). In addition, the effect of adding PP-g-MAH as a compatibiliser for the PP/NPCC nanocomposites is also studied using the internal mixer.

\section{Experimental}

\subsection{Materials and sample preparation}

The grade of PP used was Titanpro 6331 produced by Titan Polymers Malaysia Sdn. Bhd (Kuala Lumpur, Malaysia). The homoploymer PP has a density of $0.899 \mathrm{~g} / \mathrm{cm}^{3}$ and a melt flow rate of $14 \mathrm{~g} / 10$ minutes $\left(2.16 \mathrm{~kg}\right.$ at $\left.230^{\circ} \mathrm{C}\right)$. The nano calcium carbonate used was NPCC 201 supplied by NanoMaterials Pty. Ltd. The stearic acid coated nanofiller has a measured average primary particle size of about $50 \mathrm{~nm}$. The grade of PP-g-MAH added as a compatibiliser was Orevac CA 100 from 
Atofina, with a maleic anhydride content of $1 \%$. The anti-oxidant used was Irganox 1010 from Ciba Specialty Chemicals Inc.

The NPCC and PP-g-MAH were dried in a vacuum oven at $80^{\circ} \mathrm{C}$ for at least 2 hours and allowed to cool down to room temperature in a desiccator prior to use. For the melt extrusion technique, the PP/NPCC was compounded in a Berstoff (ZE-25) co-rotating twin-screw extruder $(L / D=33)$ with a barrel temperature profile ranging from $180^{\circ} \mathrm{C}$ near the hopper to $200^{\circ} \mathrm{C}$ at the die and a screw speed of $150 \mathrm{rpm}$ (rotation per minute). NPCC powder at 5, 10 and $15 \mathrm{wt} \%$ loadings and the anti-oxidant at $1 \mathrm{wt} \%$ of total compound weight were added into the molten PP via a secondary side feeder. Since the extruder is primarily designed to compound micron size fillers, the nanocomposites were compounded twice to improve and ensure homogeneous mixing. The estimated total residence time for the nanocomposites during the melt extrusion process was about 8 minutes since the nanocomposites were compounded twice by extruder.

For the melt mixing technique, mixing was carried out in batches using a Haake Rheomix 3000p internal mixer with a mixing temperature of $180^{\circ} \mathrm{C}$ and a rotor speed of $60 \mathrm{rpm}$. The PP and antioxidant were first mixed for 5 minutes before the NPCC at 5, 10 and $15 \mathrm{wt} \%$ was added slowly into the mixing chamber over a period of 10 minutes. Mixing was continued for a further 5 minutes and the homogeneous mixture was discharged from the internal mixer and later reduced into small pieces using a crusher. For the experiments using compatibiliser, the PP-g-MAH was added at a fixed amount of $10 \mathrm{wt} \%$ into the mixing chamber together with the $\mathrm{PP}$ and the anti-oxidant. The total residence time of the mixing process was 20 minutes.

The crushed pellets from the melt mixing technique and the pelletised extrudates from the melt extrusion technique were injection moulded into ISO multi-purpose test specimens using an Arburg 75 tonne injection moulding machine at $190^{\circ} \mathrm{C}$ melt temperature and $40^{\circ} \mathrm{C}$ mould temperature.

\subsection{NPCC filler content and filler dispersion}

The actual amount of filler present in the nanocomposites was determined using a thermogravimetric analyser (TGA). The analysis was performed on the samples using a Mettler Toledo TGA 851. The samples, obtained from the gate-section, mid-section and end-section of the tensile dumbell specimen, were heated from 25 to $550^{\circ} \mathrm{C}$ in an inert atmosphere of nitrogen at a heating rate of $20^{\circ} \mathrm{C} / \mathrm{min}$. The average amount of NPCC which remained at the end of the TGA scan were obtained from the thermograms to compare the amount of filler added and the actual amount present in the tested specimens.

The filler dispersion in the nanocomposites was examined using a Hitachi S-2500 Scanning Electron Microscope (SEM). The impact fractured specimens were coated with gold prior to examination under the electron beam. An operating voltage of $10 \mathrm{kV}$ and a magnification of 5000 times were used. The average size of the dispersed NPCC filler was measured on the micrographs using the Roentec ScanVision software.

\subsection{Mechanical properties evaluation}

Tensile properties were determined using an Instron 5556 Universal Testing Machine in accordance to ISO-527-1. The crosshead speed used for the modulus and tensile strength determination were 1 and $50 \mathrm{~mm} / \mathrm{min}$. respectively. Flexural properties were also measured using the same machine in accordance to ISO 178 at a crosshead speed of $2 \mathrm{~mm} / \mathrm{min}$. The notched Izod impact strength was determined using a CEAST Resil Impactor according to ISO 180 at ambient temperature. All test specimens were conditioned in accordance to ISO 291 at $25 \pm 2^{\circ} \mathrm{C}$ and $55 \pm 5 \%$ relative humidity for at least 16 hours before being tested.

To calculate the predicted modulus of composites, the weight fraction is converted to the volume fraction indicated in Equation (1):

$\phi_{f}=\frac{\rho_{c}}{\rho_{f}} W_{m}$

where $\phi_{f}$ is filler volume fraction, $\rho_{c}$ is density of composite, $\rho_{f}$ is density of filler and $W_{m}$ is filler weight fraction.

\subsection{Thermal and crystallisation studies}

The melting and crystallisation behaviour of the nanocomposites were studied using a Mettler Toledo Differential Scanning Calorimeter (DSC 822e). About $10 \mathrm{mg}$ of each sample was scanned 
from 25 to $250^{\circ} \mathrm{C}$ at a heating rate of $20^{\circ} \mathrm{C}$ per minute in an inert atmosphere of nitrogen $\left(\mathrm{N}_{2}\right)$. The $\mathrm{N}_{2}$ flow rate was set at $50 \mathrm{ml} / \mathrm{min}$. The samples were then annealed at $250^{\circ} \mathrm{C}$ for 5 minutes before being cooled to $50^{\circ} \mathrm{C}$ at a cooling rate of $20^{\circ} \mathrm{C}$ per minute. A second heating scan was performed on the cooled samples using the same parameters as the first heating cycle. The peak melting temperature $\left(T_{m}\right)$ and the enthalpy of fusion $(\Delta H)$ for the nanocomposites were obtained from the second heating curve while the peak crystallisation temperature $\left(T_{c}\right)$ was taken from the crystallisation curve. The relative crystallinity was calculated from the enthalpy value, $\Delta H$ and the enthalpy value for a theoretically $100 \%$ crystalline PP, taken as $209 \mathrm{~J} / \mathrm{g}$ [19].

\section{Results and discussions}

\subsection{NPCC filler content and dispersion}

The TGA results for the nanocomposites are given in Table 1. From the Table, the amount of NPCC measured on the specimens was also found to be close to the actual amount added during compounding and mixing.

The evaluation of filler dispersion is important as only well dispersed nanoparticles can lead to the expected improvement in mechanical properties. For the nanocomposites to possess good impact toughness, it is critical that the filler dispersion in the polymer matrix be very uniform to avoid creation of crack-initiating large agglomerates [20].

Figures 1a, 1b show the SEM micrographs of the impact-fractured surface of the nanocomposites prepared via the extruder while Figures $1 \mathrm{c}, 1 \mathrm{~d}$ are nanocomposites prepared via the internal mixer. At low NPCC content, the number of large agglomerates appeared more in the nanocomposites prepared via extrusion compared to that prepared via mixing. At higher NPCC levels, the reverse phenomenon was observed where the nanocomposites prepared by mixer have larger agglomerates compared to the extruded nanocomposites. One possible reason for this observation is that at high filler concentration, the interparticle distance between the nanofillers becomes smaller, leading to flocculation of the NPCC nanoparticles after the mixing process in the internal mixer is stopped [16]. Thus, in this study, that melt extrusion appears to be a better technique for dispersing nanofiller when the filler concentration used is high, while the internal mixer is effective for preparing nanocomposites with low filler content.

Figures 1e, 1f shows the filler dispersion of the nanocomposites prepared using the internal mixer with $10 \mathrm{wt} \%$ of PP-g-MAH added as a compatibiliser. Overall, better filler dispersion was observed in the presence of PP-g-MAH, especially at low NPCC. With PP-g-MAH, the NPCC particles appeared more encapsulated within the PP matrix, indicating that better interfacial adhesion has possibly been established between the filler and the polymer phase with the aid of the compatibiliser. Without the compatibiliser, the NPCC in the micrographs appeared more as discrete particles within the PP matrix, as shown in Figures 1c, 1d. Nevertheless, for both techniques used and even with the addition of compatibiliser, the average particle size of NPCC particles measured from the SEM micrographs were still much larger than the average primary particle size of the NPCC used in this study.

\subsection{Mechanical properties}

Figure 2 shows the effect of NPCC content on the notched Izod impact strength of the nanocomposites prepared using the internal mixing and extruder. It can be seen that for both techniques, the addition of NPCC increased the impact strength of the neat PP. However, there is a difference in the trend of increment for the two techniques. At low NPCC loading of $5 \mathrm{wt} \%$, greater increment was observed for the nanocomposites prepared via the mixer when compared to the extruder. The mixed nanocomposites appear to have smaller agglomerates, resulting in better impact improvement when compared to the composites made by melt extrusion. Nevertheless, further increase in the filler content

Table 1. TGA results of PP nanocomposites

\begin{tabular}{|c|c|c|c|}
\hline \multirow{2}{*}{$\begin{array}{c}\text { Sample composition } \\
{[\text { [wt \% PP/NPCC] }}\end{array}$} & Melt extrusion & Melt mixing & Melt mixing with 10 wt\% PP-g-MAH \\
\cline { 2 - 4 } & 4.6 & 4.7 & 4.9 \\
\hline $95 / 5$ & 9.7 & 9.4 & 9.3 \\
\hline $85 / 15$ & 14.0 & 14.1 & 14.7 \\
\hline
\end{tabular}




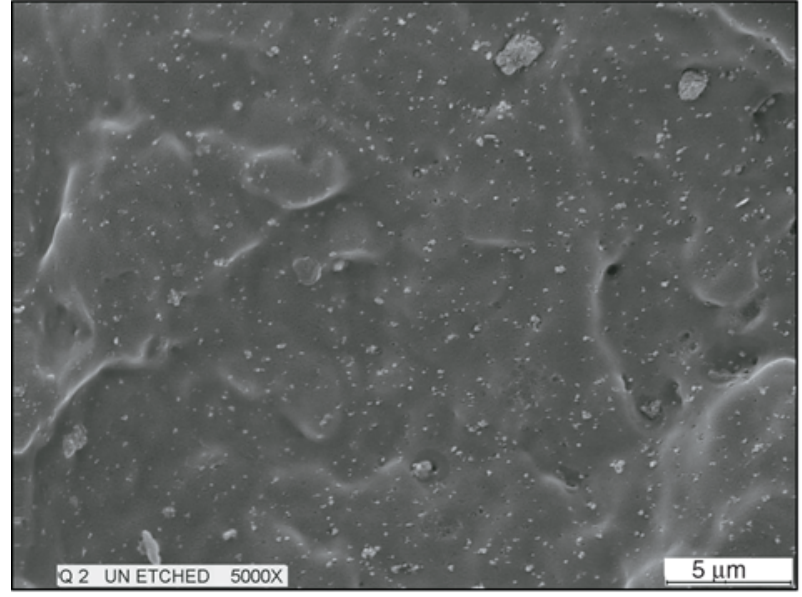

a)

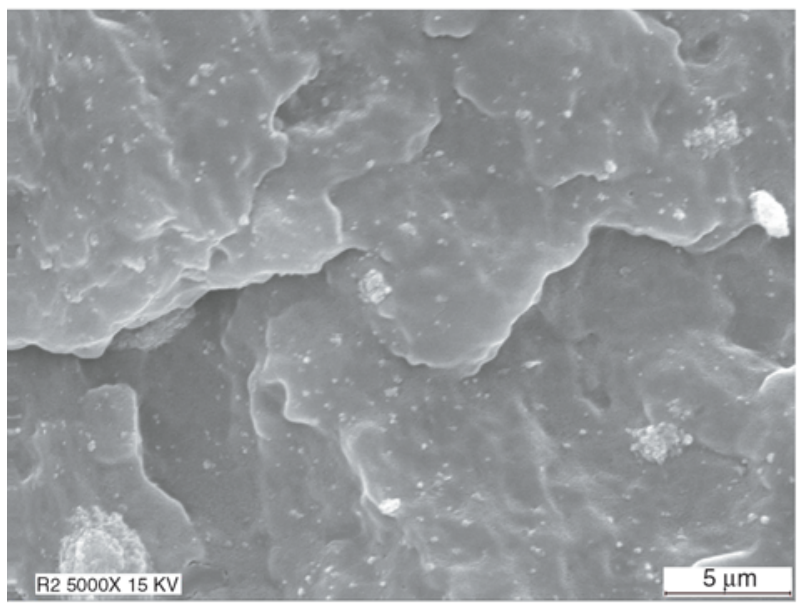

c)

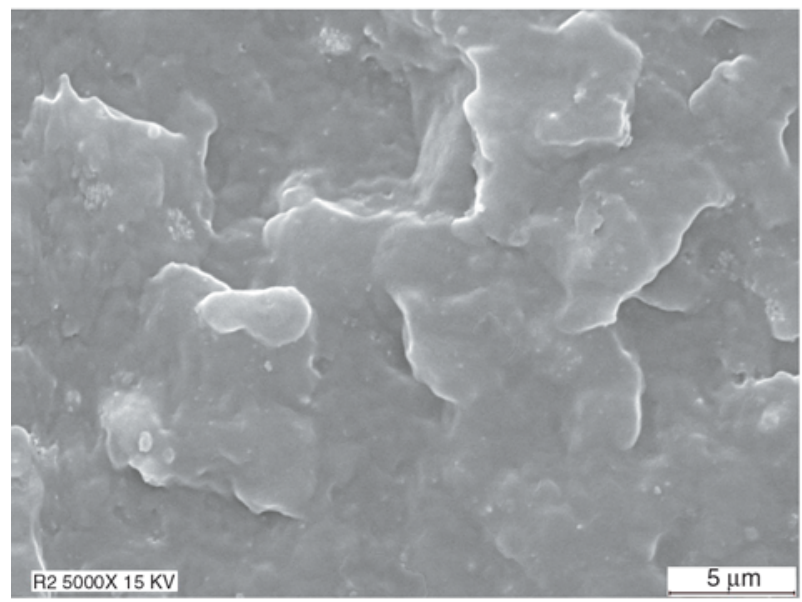

e)

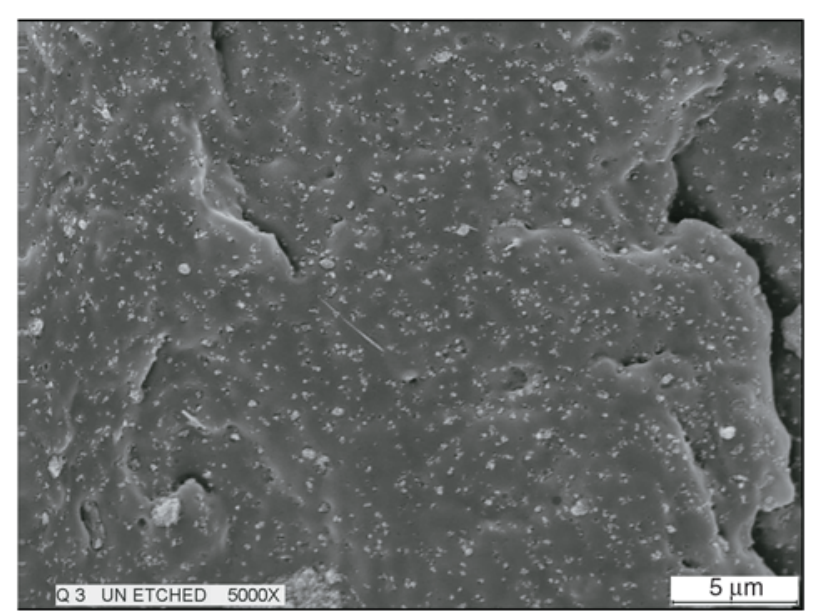

b)

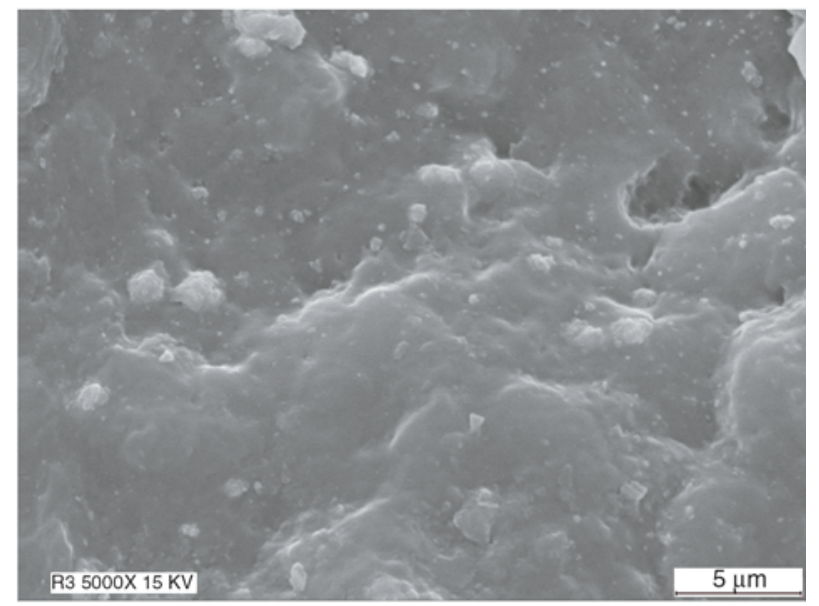

d)

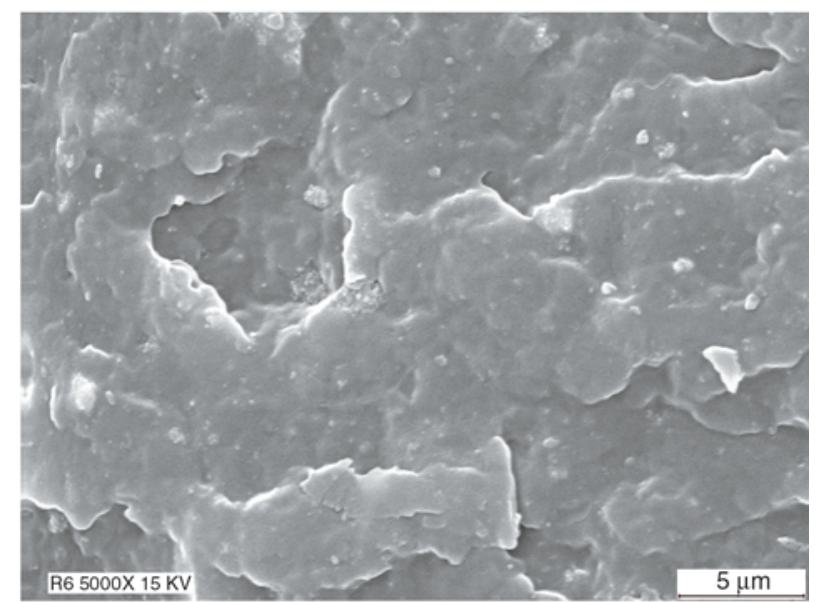

f)

Figure 1. SEM micrographs of (a) 90PP/10NPCC and (b) 85PP/15NPCC prepared using melt extrusion technique;

(c) $90 \mathrm{PP} / 10 \mathrm{NPCC}$ and (d) $85 \mathrm{PP} / 15 \mathrm{NPCC}$ prepared using melt mixing technique and (e) 90PP/10NPCC and

(f) $85 \mathrm{PP} / 15 \mathrm{NPCC}$ prepared using melt mixing technique with $10 \mathrm{wt} \% \mathrm{PP}-\mathrm{g}-\mathrm{MAH}$ as compatibiliser

for the mixed nanocomposites caused no significant changes to the impact strength. For the extruded nanocomposites, increased in impact strength was observed until addition of up to $10 \mathrm{wt} \%$ of NPCC with no further improvement observed thereafter. The result of the impact strength is consistent with the SEM micrographs results shown earlier in Figures 1a-1d).

It can also be seen that addition of PP-g-MAH has improved the impact strength of PP at all filler loadings. However, the same trend is observed whereby after filler loading of $5 \mathrm{wt} \%$, the impact 


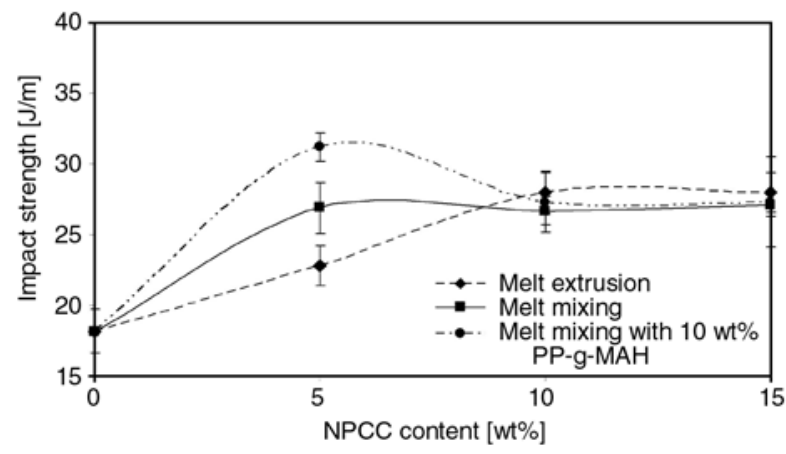

Figure 2. Effect of NPCC and preparation techniques on the impact strength of nanocomposites

strength drops, even in the presence of the compatibiliser. As indicated earlier, at higher concentrations, the mixer does no longer provide effective mixing, thus the addition of the compatibizer does not improve the impact strength. The SEM micrographs as shown in Figures 1e, if support the impact results. At higher filler loading, the number of large agglomerates was more apparent and thus contributing to the lowering of the impact strength. The effect of NPCC on the flexural modulus of the mixed and extruded nanocomposites is shown in Figure 3. Predictably, the stiffness of PP increased gradually with increasing filler weight fraction. There also appears to be no significant difference between the flexural modulus of the nanocomposites prepared using the two different techniques, indicating that the modulus of the nanocomposites is not significantly affected by the presence of filler agglomerates. Presence of PP-g-MAH in the mixed nanocomposites has also significantly improved the modulus further, This may be attributed to the improved interfacial adhesion between the filler particles and the PP matrix.

The effect of NPCC on the tensile strength of the nanocomposites prepared via mixing and extrusion

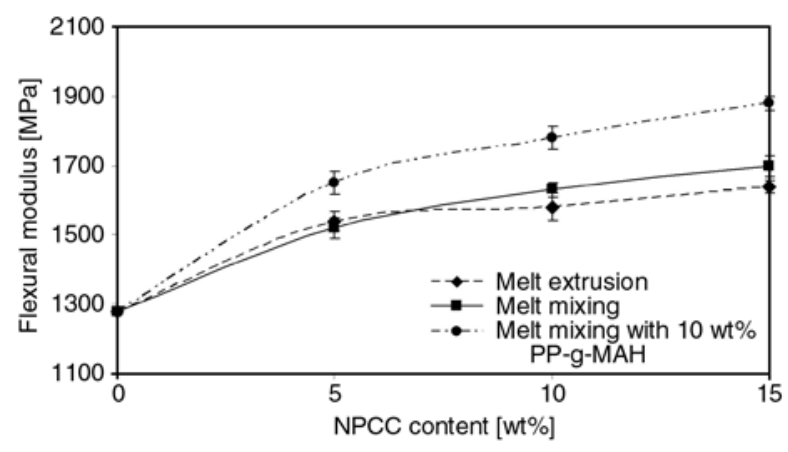

Figure 3. Effect of NPCC and preparation techniques on the flexural modulus of nanocomposites

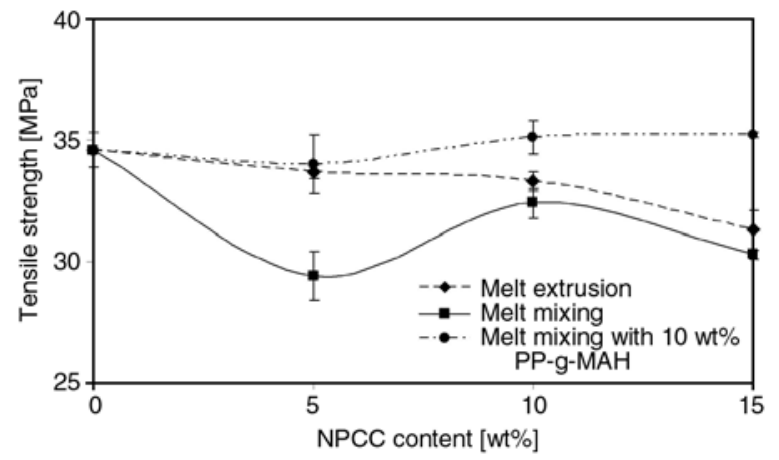

Figure 4. Effect of NPCC and preparation techniques on the tensile strength of nanocomposites

is shown in Figure 4. In general, the tensile strength of the nanocomposites prepared by both techniques decreases with increasing amount of NPCC and from among the two techniques, the drop in tensile strength was higher for the mixed nanocomposites compared to the extruded nanocomposites. In the presence of the $10 \mathrm{wt} \%$ PP-g-MAH as a compatibiliser, the tensile strength of the nanocomposites did not deteriorate with increasing NPCC concentration. According to Liang [24], the strength of particulate-filled polymer composites depends, to a great extent, on the interfacial adhesion between the matrix and the filler which will facilitate the transfer of a small section of stress to the filler particle during deformation.

An equation which is commonly used to predict the modulus of composites containing a certain amount of spherical fillers developed by Guth [22] is shown as Equation (2):

$E_{c}=E_{m}\left(1+2.5 \phi_{f}+14.1 \phi_{f}^{2}\right)$

where $E_{c}$ is the Young's modulus of the composite, $E_{m}$ is the matrix Young's modulus and $\phi_{f}$ is the volume fraction of the filler. It has been reported that Equation (1) is only applicable to composites filled with a certain amount of spherical fillers. If the filler concentration is higher than $10 \mathrm{vol} \%$, the modulus increases much more rapidly than Equation (2) would predict, attributed to the formation of a network by the spherical filler chains [23]. The modulus of particle-filled composites may also be predicted using Equations (3) or (4) [18]:

$$
\begin{aligned}
& E_{c}=E_{p} \phi_{p}+E_{f} \phi_{f} \\
& E_{c}=\frac{E_{p} E_{f}}{E_{p} \phi_{f}+E_{f} \phi_{p}}
\end{aligned}
$$


where $E_{c}$ is the modulus of the composites, $E_{p}$ and $E_{f}$ are the moduli of the polymer matrix and the filler respectively, $\phi_{p}$ and $\phi_{f}$ are the volume fraction of the polymer and filler respectively. Equation (3), based on the rule of mixtures, is appropriate when strong adhesion exists between the filler and the polymer and the filler has a large aspect ratio.

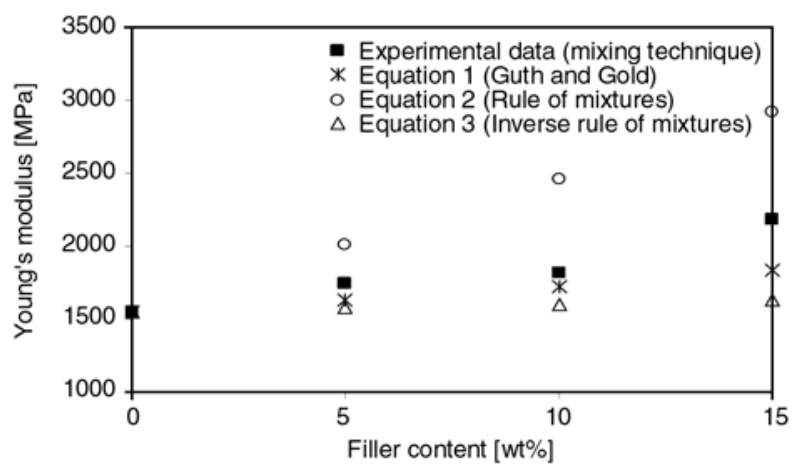

Figure 5. The calculated (theoretical) and measured (experimental) moduli of PP/NPCC nanocomposites prepared via melt extrusion as a function of filler content. Note: The modulus of NPCC is taken as $26 \mathrm{GPa}$ [16].

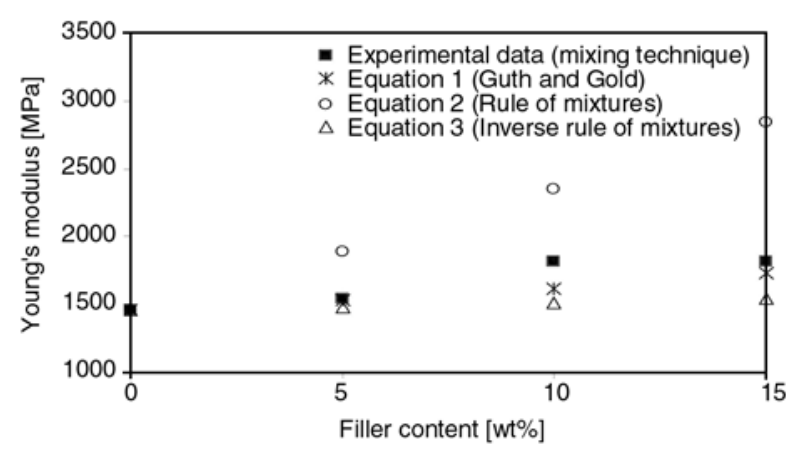

Figure 6. The calculated (theoretical) and measured (experimental)moduli of PP/NPCC nanocomposites prepared via melt mixing as a function of filler content

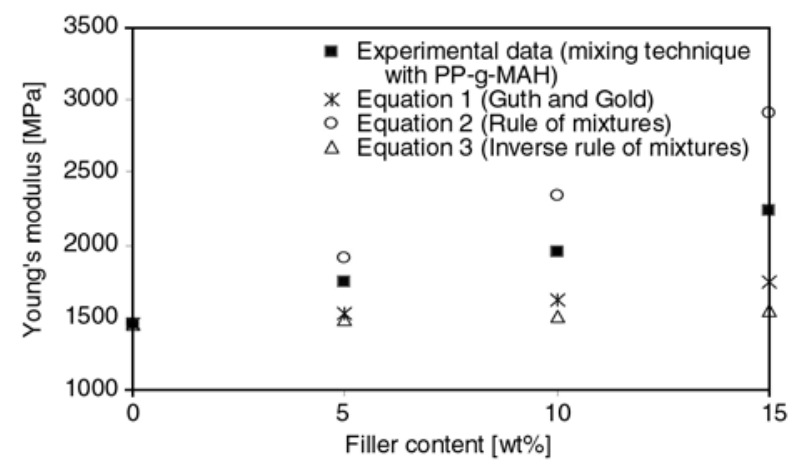

Figure 7. The calculated (theoretical) and measured (experimental) moduli of PP/NPCC nanocomposites prepared via melt mixing with $\mathrm{PP}-\mathrm{g}$ MAH as a function of filler content
Equation (4), the inverse rule of mixtures equation, is applicable to rigid spherical particles.

Figures 5-7 illustrate the experimental and calculated modulus based on the above equations for the extruded, mixed and mixed with PP-g-MAH nanocomposites, respectively. It can be seen from Figure 5 that the experimental moduli of the extruded nanocomposites agree quite well with Equations (2) and (4) up till a filler content of $10 \mathrm{wt} \%$. Equation (3) was found to be the most inaccurate to predict the moduli of the nanocomposites, indicating that the law of mixtures is invalid in this case as the equation is only applicable when the filler has a large aspect ratio and there is a strong bonding between the matrix and the filler. A similar observation is made for the mixed nanocomposites in Figure 6, where the experimental plots closely follow Equations (2) and (4), and deviate from Equation (3). However, it is interesting to note that the experimental moduli of the mixed nanocomposites still follow Equations (2) and (3) even at high filler loadings of $15 \mathrm{wt} \%$. For the mixed nanocomposites with PP-g-MAH, the experimental moduli, as shown in 8 , were found to deviate from Equations (2) and (4) and showed tendency to move towards Eqquation (3). These results indicate that better adhesion has occurred between the NPCC and the PP matrix, as Equation (3) is appropriate when strong adhesion exist between the filler and the polymer.

\subsection{Thermal and crystallisation behaviour}

The DSC melting curves for the nanocomposites are shown in Figures 8a-8c, and their corresponding melting temperatures $\left(T_{m}\right)$ are listed in Table 2. From the DSC curves, the $T_{m}$ of the neat PP was found to be $163^{\circ} \mathrm{C}$ while the $T_{m}$ of the nanocomposites ranged from 161 to $164^{\circ} \mathrm{C}$. Thus, incorporation of NPCC did not result in a significant shift in the $T_{m}$ of PP, as the small variation of observed is within the experimental error of the instrument used.

However, it is interesting to note that the DSC curves for PP filled with 10 and $15 \mathrm{wt} \%$ of NPCC prepared with $\mathrm{PP}-\mathrm{g}-\mathrm{MAH}$ using the internal mixer displayed a small melting depression at about $150^{\circ} \mathrm{C}$. This small endothermic transition is possibly associated with the melting of the $\beta$-phase crystallites of PP $[17,25,26]$. PP is a polymorphic 

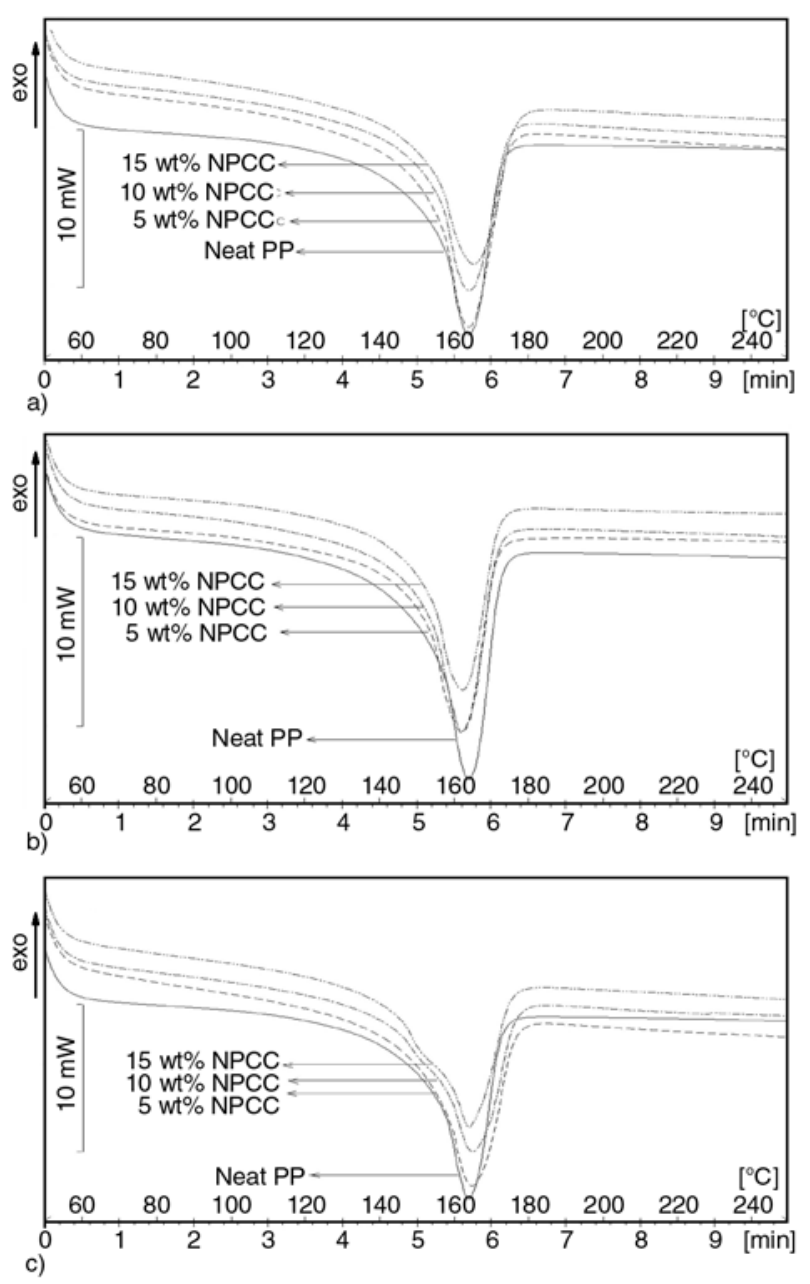

Figure 8. DSC melting curves for nanocomposites prepared via (a) melt extrusion, (b) melt mixing and (c) melt mixing with $10 \mathrm{wt} \% \mathrm{PP}-\mathrm{g}-\mathrm{MAH}$ compatibiliser

material and is capable of crystallising in three different crystal forms; the $\alpha$, or monoclinic form, the $\beta$, or pseudo-hexagonal form, and the $\gamma$, or triclinic form. The most stable and prevalent form is the $\alpha$-phase. This phase, which melts at around $160^{\circ} \mathrm{C}$, is the main crystalline structure formed under normal processing conditions while the $\beta$-phase is obtained if the melt undergoes high shear forces during processing [26]. The $\beta$-phase PP could also be formed in the presence of nucleating agents. Thus, the PP-g-MAH compatibiliser has possibly improved the nucleating activity of the NPCC and hence promoting the formation of the $\beta$-phase PP, which was not present in the mixed compound prepared without the compatibiliser.

Results of the enthalpy of fusion $(\Delta H)$ obtained from the melting curves for the PP and the nanocomposites are listed in Table 2. It should be noted that the $\Delta H$ values shown have been corrected for filler content, thus expressed in J/g polymer (PP). The relative crystallinity of the nanocomposites were then calculated using the $\Delta H$ values, taking $209 \mathrm{~J} / \mathrm{g}$ as the theoretical enthalpy value for a $100 \%$ crystalline PP [19]. Overall, it is observed that the crystallinity of PP is not appreciably affected by the addition of the NPCC filler, as the $\pm 2 \%$ variation in the crystallinity values observed is within the experimental error of the instrument used.

The DSC crystallisation curves for PP and the nanocomposites are shown in Figures $9 \mathrm{a}-9 \mathrm{c}$ and the peak crystallisation temperature $\left(T_{c}\right)$ values are listed in Table 2. For the nanocomposites prepared via extrusion and mixing without the presence of PP-g-MAH as compatibiliser, there appears to be minimal shift in the $T_{c}$, indicating again the weak nucleating effect of NPCC particles on the crystallisation of PP. However, addition of PP-g-MAH into the mixed nanocomposites has induced crystallisation of PP to occur at higher temperatures resulting in higher $T_{c}$. Thus, these DSC results suggest that PP-g-MAH has improved the nucleation

Table 2. DSC results for the nanocomposites

\begin{tabular}{|c|c|c|c|c|}
\hline $\begin{array}{c}\text { Sample composition } \\
\text { [wt \% PP/NPCC] }\end{array}$ & $\begin{array}{c}\text { Melting } \\
\text { temperature, } \mathbf{T}_{\mathbf{m}}\left[{ }^{\circ} \mathbf{C}\right]\end{array}$ & $\begin{array}{l}\text { Enthalpy of fusion corrected for } \\
\text { filler content, } \Delta \mathbf{H}_{\mathbf{c}}[\mathrm{J} / \mathrm{g} \mathrm{PP}]\end{array}$ & $\begin{array}{c}\text { Percentage } \\
\text { crystallinity, } \mathbf{X}_{\mathbf{c}}[\%]\end{array}$ & $\begin{array}{c}\text { Crystallisation } \\
\text { temperature, } \mathbf{T}_{\mathrm{c}}\left[{ }^{\circ} \mathrm{C}\right]\end{array}$ \\
\hline $100 / 0$ & 163 & 78 & 37 & 109 \\
\hline \multicolumn{5}{|c|}{ Melt extrusion } \\
\hline $95 / 5$ & 161 & 74 & 35 & 110 \\
\hline $90 / 10$ & 161 & 73 & 35 & 111 \\
\hline $85 / 15$ & 162 & 73 & 35 & 112 \\
\hline \multicolumn{5}{|c|}{ Melt mixing } \\
\hline $95 / 5$ & 162 & 79 & 38 & 115 \\
\hline $90 / 10$ & 163 & 80 & 38 & 113 \\
\hline $85 / 15$ & 164 & 81 & 39 & 112 \\
\hline \multicolumn{5}{|c|}{ Melt mixing with PP-g-MAH } \\
\hline $95 / 5$ & 164 & 76 & 36 & 118 \\
\hline $90 / 10$ & 164 & 78 & 37 & 118 \\
\hline $85 / 15$ & 163 & 80 & 38 & 120 \\
\hline
\end{tabular}



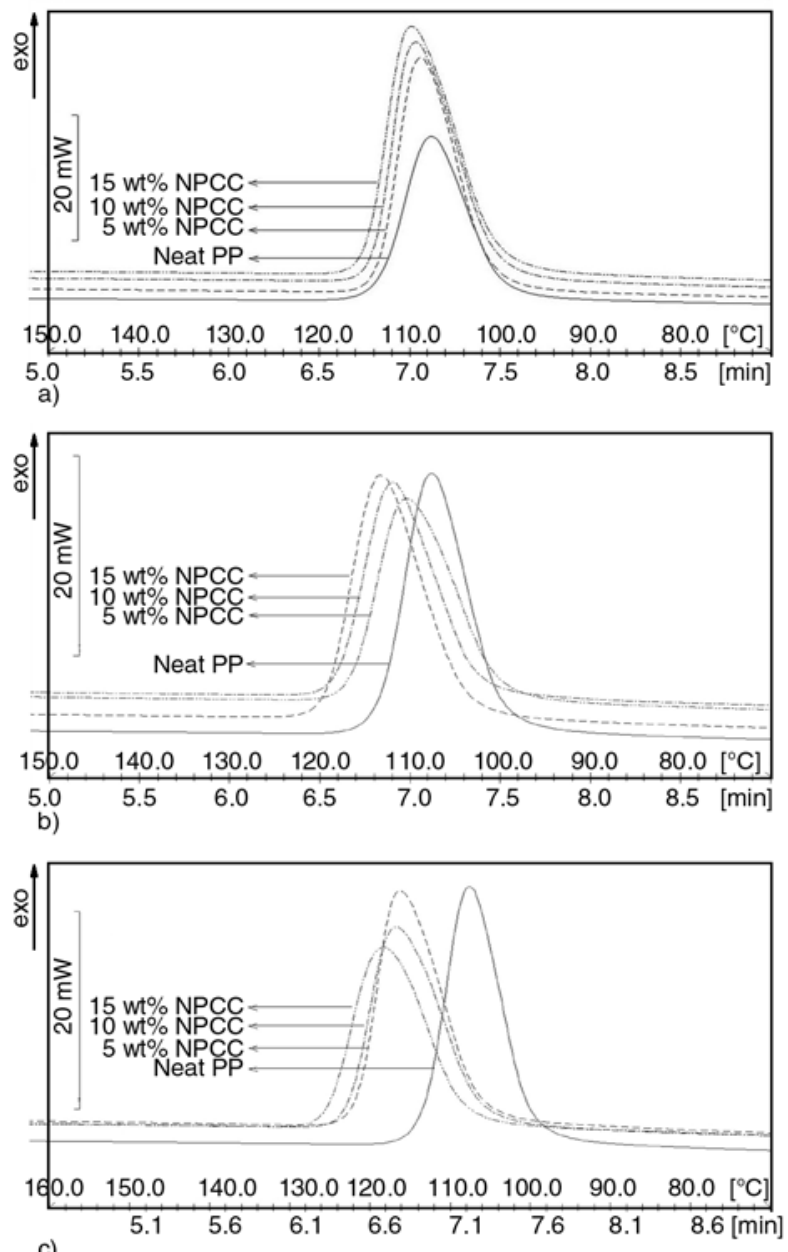

Figure 9. DSC crystallisation curves for nanocomposites prepared via (a) melt extrusion, (b) melt mixing and (c) melt mixing with $10 \mathrm{wt} \%$ PP-g-MAH compatibiliser

effect of the nano NPCC particles. In the presence of the compatibiliser, closer interaction between the NPCC particles and the PP matrix has possibly been established and the better dispersed particles has provided more sites for the nucleation of PP to begin.

\section{Conclusions}

The choice of processing technique has some influence on the properties of the PP/NPCC nanocomposites. The extrusion technique was found to be more effective to disperse the nanofillers when the filler concentration is high, resulting in slightly better impact and tensile strength. Better impact strength was found to be associated with less amount of filler agglomeration as evident from the
SEM micrographs. The use of internal mixer was found to be more suitable when the filler concentration used is low. There was no significant difference in the flexural modulus of the nanocomposites using the two different techniques, indicating that the modulus is not significantly affected by the presence of filler agglomerates.

Introduction of PP-g-MAH as compatibiliser for the nanocomposites prepared via mixing improved the filler dispersion, resulting in better impact, modulus and tensile strength. The improvement in impact strength is most likely attributed to the better filler dispersion while the increased tensile strength and modulus may be due to better interfacial adhesion between the filler and the PP matrix. DSC results show that the PP-g-MAH has also improved the nucleating activity of the NPCC, inducing crystallisation of PP to occur at higher temperatures.

\section{Acknowledgements}

The authors would like to thank the Ministry of Science, Technology and Innovation (MOSTI), Malaysia for the IRPA research grant (project no.03-01-01-0052-EA001). The authors would also like to thank Zalena Saem and Azura Ruhan for their kind assistance in conducting the SEM analysis.

\section{References}

[1] Krawczak P.: Compounding and processing of polymer nanocomposites: From scientific challenges to industrial stakes. Express Polymer Letters, 1, 188 (2007). DOI: $10.3144 /$ expresspolymlett.2007.29

[2] Jordan J., Jacob K. I., Tannenbaum R., Sharaf M. A., Jasiuk I.: Experimental trends in polymer nanocomposites - A review. Materials Science and Engineering A, 393, 1-11 (2005). DOI: $10.1016 /$ j.msea.2004.09.044

[3] Kaempfer D., Thomann R., Mülhaupt R.: Melt compounding of syndiotactic polypropylene nanocomposites containing organophilic layered silicates and in situ formed core/shell nanoparticles. Polymer, 43, 2909-2916 (2002). DOI: $\underline{10.1016 / \mathrm{S} 0032-3861(02) 00113-1}$

[4] Rong M. Z., Zhang M. Q., Zheng Y. X., Zeng H. M., Friedrich K.: Improvement of tensile properties of nano- $\mathrm{SiO}_{2} / \mathrm{PP}$ composites in relation to percolation mechanism. Polymer, 42, 3301-3304 (2001). DOI: $10.1016 / \mathrm{S} 0032-3861(00) 00741-2$ 
[5] Yang K., Yang Q., Li G., Sun Y., Feng D.: Morphology and mechanical properties of polypropylene/calcium carbonate nanocomposites. Materials Letters, 60, 805-809 (2006). DOI: $10.1016 /$ j.matlet.2005.10.020

[6] López D. G., Picazo O., Merino J. C., Pastor J. M.: Polypropylene-clay nanocomposites: Effect of compatibilizing agents on clay dispersion. European Polymer Journal, 39, 945-950 (2003). DOI: $10.1016 / \mathrm{S} 0014-3057(02) 00333-6$

[7] Wu C. L., Zhang M. Q., Rong M. Z., Friedrich K.: Tensile performance improvement of low nanoparticles filled-polypropylene composites. Composites Science and Technology, 62, 1327-1340 (2002). DOI: $10.1016 / \mathrm{S} 0266-3538(02) 00079-9$

[8] Kashiwagi T., Grulke E., Hilding J., Harris R., Awad W., Douglas J.: Thermal degradation and flammability properties of polypropylene-carbon nanotube composites. Macromolecular Rapid Communications, 23, 761-765 (2002).

DOI: $\underline{10.1002 / 1521-3927(20020901) 23: 13<761:: A I D-}$ MARC761>3.0.CO;2-K

[9] Gorna K., Hund M., Vucak M., Gröhn F., Wegner G.: Amorphous calcium carbonate in form of spherical nanosized particles and its application as fillers for polymers. Materials Science and Engineering A, 477, 217-225 (2008).

DOI: $10.1016 /$ j.msea.2007.05.045

[10] Liang J. Z.: Evaluation of dispersion of nano- $\mathrm{CaCO}_{3}$ particles in polypropylene matrix based on fractal method. Composites Part A: Applied Science and Manufacturing, 38, 1502-1506 (2007).

DOI: $10.1016 /$ j.compositesa.2007.01.011

[11] Xie X-L., Liu Q-X., Li R. K-Y., Zhou X-P., Zhang QX., Yu Z-Z., Mai Y-W.: Rheological and mechanical properties of $\mathrm{PVC} / \mathrm{CaCO}_{3}$ nanocomposites prepared by in situ polymerization. Polymer, 45, 6665-6673 (2004).

DOI: 10.1016/j.polymer.2004.07.045

[12] Di Lorenzo M. L., Errico M. E., Avella M.: Thermal and morphological characterization of poly(ethylene terephthalate)/calcium carbonate nanocomposites. Journal of Materials Science, 37, 2351-2358 (2002). DOI: $10.1023 / \mathrm{A}: 1015358425449$

[13] Gilbert M.: Surface treatments for particulate fillers in plastics. in 'Plastics additives: An A-Z reference' (ed.: Pritchard G.) Chapman and Hall, London, 590-603 (1998).

[14] Pukánszky B.: Particulate filled polypropylene: Structure and properties. in 'Polypropylene: structure, blends and composites' (ed.: Karger-Kocsis J.) Chapman and Hall, London, 2-70 (1995).
[15] Roberts D., Constable R. C.: Chemical coupling agents for filled and grafted polypropylene composites. in 'Handbook of polypropylene and polypropylene composites' (ed.: Karian H. G.) Marcel Decker, New York, 28-68 (2003).

[16] Chen J. H., Rong M. Z., Ruan W. B., Zhang M. Q.: Interfacial enhancement of nano- $\mathrm{SiO}_{2} /$ polypropylene composites. Composites Science and Technology, 69, 252-259 (2008).

DOI: 10.1016/j.compscitech.2008.10.013

[17] Chan C-M., Wu J., Li J-X., Cheung Y-K.: Polypropylene/calcium carbonate nanocomposites. Polymer, 43, 2981-2992 (2002). DOI: $10.1016 / \mathrm{S} 0032-3861(02) 00120-9$

[18] Wang Y., Shen H., Li G., Mai K.: Effect of Interfacial interaction on the crystallization and mechanical properties of $\mathrm{PP} /$ nano- $\mathrm{CaCO}_{3}$ composites modified by compatibilizers. Journal of Applied Polymer Science, 113, 1584-1592 (2009).

DOI: $10.1002 /$ app. 30057

[19] Galeski A.: Crystallization. in 'Polypropylene: An A-Z reference' (ed.: Karger-Kocsis J.) Kluwer, Dordrecht, 135-141 (1999).

[20] Thio Y. S., Argon A. S., Cohen R. E., Weinberg M.: Toughening of isotactic polypropylene with $\mathrm{CaCO}_{3}$ particles. Polymer, 43, 3661-3674 (2002). DOI: 10.1016/S0032-3861(02)00193-3

[21] Zhang Q-X., Yu Z-Z., Xie X-L., Mai Y-W.: Crystallization and impact energy of polypropylene/ $\mathrm{CaCO}_{3}$ nanocomposites with nonionic modifier. Polymer, 45, 5985-5994 (2004).

DOI: 10.1016/j.polymer.2004.06.044

[22] Guth E. J.: Theory of filler reinforcement. Journal of Applied Physics, 16, 20-25 (1945).

DOI: $\underline{10.1063 / 1.1707495}$

[23] Wu Y-P., Jia Q-X., Yu D-S., Zhang L-Q.: Modeling Young's modulus of rubber-clay nanocomposites using composite theories. Polymer Testing, 23, 903 909 (2004).

DOI: 10.1016/j.polymertesting.2004.05.004

[24] Liang J-Z.: Toughening and reinforcing in rigid inorganic particulate filled poly(propylene): A review. Journal of Applied Polymer Science, 83, 1547-1555 (2001).

DOI: $10.1002 / a p p .10052$

[25] Mudra I.: Structure formation in crystalline polymers in presence of nucleating agents. PhD Thesis, Technical University of Budapest, Hungary (1996).

[26] Lozano T., Lafleur P. G., Grmela M., Thibodeau C.: Effect of filler dispersion on polypropylene morphology. Polymer Engineering and Science, 44, 880-890 (2004). DOI: $10.1002 /$ pen.20079 